\title{
An Evaluative Study of Machine Translation in the EFL Scenario of Saudi Arabia
}

\author{
Raneem Khalid Al-Tuwayrish \\ College of Science and Arts, Methnab, Qassim University, Saudi Arabia \\ E-mail: Ro0557ro@hotmail.com
}

Doi:10.7575/aiac.alls.v.7n.1p.5

Received: 25/08/2015

URL: http://dx.doi.org/10.7575/aiac.alls.v.7n.1p.5

Accepted: 27/10/2015

\begin{abstract}
Artificial Intelligence or AI as it is popularly known and its corollary, Machine Translation (MT) have long engaged scientists, thinkers and linguists alike in the twenty first century. However, the wider question that lies in the relation between technology and translation is, What does technology do to language? This is an important question in the current paradigm because new translation technologies, such as, translation memories, data-based machine translation, and collaborative translation, far from being just additional tools, are changing the very nature of the translators' cognitive activity, social relations, and professional standing. In fact, in some translation situations such as when translating technical materials or subject matter that are not a specialization with human translators, one potentially needs technology. The purview of this paper, however, is limited to the role of MT in day to day situations where the generic MT tools like Google Translate or Bing Translator are encouraged. Further, it endeavours to weigh and empirically demonstrate the pros and cons of MT with a view to recommending measures for better communication training in the EFL set up of Saudi Arabia.
\end{abstract}

Keywords: AI, MT, translation, technology, necessity, communication

\section{Introduction}

The world today has come to represent a global village. This is a result of greater human traffic across countries and continents for reasons of trade, commerce, education and tourism. Among other factors, what has aided this migration is the availability of technology: the widespread use of computers and its tools have made it possible for populace to work or live in foreign surroundings. One cannot think of a life bereft of the world wide web and email in this world. Thus we can surmise that technology is no longer an option for us, but a necessity.

Today we live in a world where the use of technology dominates everything we do. One of the most important features that we get from the field of technology is ease and speed of doing everything. Demands of communication and effective use of world literatures in virtually all fields of life have compelled us to look for quality translations in our mother tongues. It is with this background that this paper endeavours to study the role of machine translation in the world of language and communication.

\subsection{Defining Translation}

Merriam Webster defines 'Translation' as an act, process, or instance of translating: as. a: a rendering from one language into another; also : the product of such a rendering. b: a change to a different substance, form, or appearance : conversion.

Broadly, there are four types of translation:

1) Human translation

2) Machine translation

3) Machine-Aided Human Translation

4) Human-Aided Machine Translation

Whereas, the first three are familiar terms, Human aided Machine Translation is an outcome of very recent developments in the field and has been discussed later in this paper. However, irrespective of the type of translation tool employed, a good translation is the one which seems to be natural and not 'transferred' from another place (ref). This paper will focus on the type of translation which is basically based on technology and, that is, Machine Translation.

According to linguists, Machine translation, sometimes referred to by the abbreviation, MT, is a sub-field of computational linguistics that investigates the use of software to translate text or speech from one natural language to another. The need for machine translation has been increasing due to the growing need for translation in the wake of globalization, and the growing importance of communication. 


\section{Literature Review}

Since the paper has as its focus on Machine Translation, it would be apt to begin by citing what the software giant Microsoft has to say about it. According to Microsoft,

"The principal focus of the Natural Language Processing group is to build a machine translation system that automatically learns translation mappings from bilingual corpora.

The Machine Translation (MT) project at Microsoft Research is focused on creating MT systems and technologies that cater to the multitude of translation scenarios today. Data driven systems, in particular those with a statistical core engine, have proven to be the most efficient, due to their ability to adapt to a wide domain coverage and being trained in new language pairs within a matter of weeks. This team works closely with research and development partners worldwide, making the system accessible to a variety of products and services."

Further, "Machine Translation has been a major focus of the NLP group since 1999. Our approach to MT has always been "data-driven". Rather than writing explicit rules to translate natural language, we train our algorithms on humantranslated parallel texts, which allows them to automatically learn how to translate. Our first generation Logical Form based system learned translation patterns at the level of abstract parsed structures, and was used to translate the entire Microsoft support knowledge base into several languages. Our recent research has focused on Statistical Machine Translation (SMT).

Syntax-Based SMT. Translating content from English into as many foreign languages as possible is a high priority for Microsoft, not to mention the billions of people around the world who do not read English. The Treelet Translation System leverages an English natural language parser to help guide this process. This technology is currently used in several places across Microsoft, including the Live translation system for computer-related texts and the Microsoft

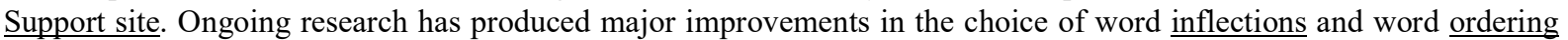
in this system.

Phrase-Based SMT. Many leading SMT systems do not use any linguistic resources, such as dictionaries, grammars, or parsers. These so called "phrase-based" systems try to learn translations of arbitrary word sequences of words directly from parallel texts. By improving the methods used to prune the search for the best translation in this type of system, we have shown how to find better translations in less time than previous systems.

Word Alignment. SMT systems learn translations from existing bodies of translated data. For most modern systems, identifying the word correspondences or word alignments in this translated data is a crucial step in training systems. Our group has produced pioneering work in both discriminative and generative approaches to word alignment, resulting in faster alignment algorithms with state-of-the-art quality.

Language Modeling. Large n-gram language models are a crucial component in high-quality SMT systems. Trained on only target language data, they help translation systems select fluent and readable output. MSRLM is a publiclyavailable language modeling toolkit developed at MSR. The toolkit is both fast and scalable, training a 5-gram model from more than one billion pre-tokenized words in about 3 hours on a single machine."

Bar Hillel (1953) clearly states that MT should aim at rendering meaning, not words: A comment on what machines were doing in the name of translation. In a similar vein, he says that FAHQT (Fully Automatic High Quality Translation) "is impossible not only in foreseeable future but in principle".

Christian Rohrer (1953), in his paper on MT concludes with saying that, MT as a research project cuts across traditional disciplinary and institutional boundaries. Theoretical linguists, lexicographers and computer scientists must cooperate in order to solve some of the problems of (machine) translation. Grammars and dictionaries used in MT should be based on linguistic theories which are widely accepted in the linguistic community. The linguistic theories should be expressed in formalisms that fulfil the requirements of a good programming language. An open and transparent discussion between linguists and computer scientists will lead to a realistic assessment of the possibilities and prospects for MT.

The well-known ALPAC (Automatic Language Processing Advisory Committee), a committee of seven scientists established in 1964 by the US government 'to evaluate the progress in computational Linguistics in general and Machine Translation in particular', concluded in 1966 that MT funding was money wasted. Their main objection to it was that it was irrationally expensive and hence not usable on a large scale. Also it needed too much post-processing and the need for translation was really small scale and that, too, well covered by humans.

Ralph Grishman (1973), in his pioneering work on Natural Language Processing, succinctly enunciates on the status and future of MT: Work on MT began in the late 1950s with high hopes and little realization of the difficulties involved. Problems in MT stimulated work in both linguistics and computational linguistics, including some of the earliest parsers. Extensive work was done in the early 1960s, but a lack of success, and in particular, a realization that fully automatic high quality translation would not be possible without fundamental work on text 'understanding', led to a cutback of funding.

In an article interestingly named, The Proper Place of Men and Machines in Language, Martin Kay (1997) says, “The only way in which the power of computers has been brought to bear on the problem of language translation is machine translation, that is, the automation of the entire process. Machine translation is an excellent research vehicle but stands no chance of filling actual needs for translation which are growing at a great rate. In the quarter century during which work on machine translation has been going on, there has been considerable progress in relevant areas of computer 
science". Further, and more significantly to the current study, "advances in Linguistics, important though they may have been, have not touched the core of this problem. The proper thing to do is therefore, to adopt the kind of solutions that have proved successful in other domains, namely to develop cooperative man-machine systems (bold is mine)".

According to Koehn (2004), "To adequately evaluate the quality of any translation is difficult, since it is not entirely clear what the focus of the evaluation should be. Surely, a good translation has to adequately capture the meaning of the foreign original. However, pinning down all the nuances is hard, and often differences in emphasis are introduced based on the interpretation of the translator. At the same time, it is desirable to have fluent output that can be read easily. These two goals, adequacy and fluency, are the main criteria in machine translation evaluation."

Helena Hoppe (2005), drawing from Arnold (2003: 1-2) succinctly lists the limitations of MT as the following:

First of all, we cannot expect the translations to be perfect, i.e. to look polished. This would require post-editing by a human translator. However, we should be able to expect a text which is correct grammatically and which has approximately the same meaning as the source text. "Approximately" due to the fact that languages express content differently. This will be explained further in later sections.

Secondly, we will definitely come across problems when there is new terminology in the source text. Translators are sometimes faced with the task of creating new expressions in the target language for a new phenomenon. This cannot be expected of a computer since it requires creativity and learning, something which we have previously established that computers are incapable of.

Additionally, and this ties in with the second point, there may be phenomena in the source text which do not exist in the culture where the target text will be read. A translator would usually insert some type of explanation in the target text, i.e. act as some type of "cultural mediator" (Arnold 2003:2). This, however, can also not be expected of a computer.

Due to these factors, one should have realistic expectations when examining examples of machine translation.

Further, in the same paper, the writer quotes Martin Kay (2005) who says that "translation is not primarily a linguistic operation." She clarifies that "What he means by --this is that making a good translation, apart from requiring linguistic knowledge, also calls for a great deal of knowledge about the world'.

\section{Research problem}

1. The problem of this study is expressed in the form of the following questions which the study attempts to answer: Is MT a boost or an impediment in communication?

2. What are the conditions, if any, where MT is a useful tool?

3. Can MT completely replace human translation?

\section{Methodology}

Forty undergraduate students of English (twenty each from Levels 5ans 8) at Qassim University were identified as subjects. Four random passages in English were shortlisted: Two of these dealt with scientific processes and the other two were English versions of world history lessons. Each passage was a unique sample. Thus, there were in all four unique passages, all of them in English. Ten students each from the Humanities were assigned the same world history passage while the remaining ten were allotted the other passage. The same technique was used while assigning the scientific process passages to the level 5 undergrads. The groups were named 8.1 and 8.2 for level 8, and 5.1 and 5.2 for Level 5 students. Both groups 1 were control groups and were asked to translate the passages given to them using human means (which could also include seeking the help of seniors or teachers). Groups 2 were asked to employ any of the machine translation services available to them. A time frame of three days was allotted for the exercise. At the expiry of the duration, randomly selected two responses each from the four groups (making a total of eight responses) were evaluated by five proficient bilingual users of Arabic and English: Three were professional interpreters and two were teachers. They were to grade the translations on a qualitative scale: Very good; good; average; bad; incomprehensible. The evaluations were consolidated. Here are the results:

\begin{tabular}{|l|l|l|l|l|l|}
\hline 8.1 & $\begin{array}{l}\text { Very } \\
\text { good }\end{array}$ & Good & Average & Bad & Incomprehensible \\
\hline 1 & & & $\mathbf{V}$ & & \\
\hline 2 & & $\mathbf{V}$ & & & \\
\hline 3 & & $\mathbf{V}$ & & & \\
\hline 4 & & & $V$ & & \\
\hline 5 & & & $\mathbf{V}$ & & \\
\hline 6 & & & $\mathbf{V}$ & & \\
\hline 7 & & $\mathbf{V}$ & & & \\
\hline
\end{tabular}




\begin{tabular}{|c|c|c|c|c|c|}
\hline 8 & & $\nabla$ & & & \\
\hline 9 & & $\boldsymbol{V}$ & & $V$ & \\
\hline 1 & & $V$ & & & \\
\hline 8.2 & $\begin{array}{l}\text { Very } \\
\text { good }\end{array}$ & Good & Average & $\mathrm{Bad}$ & Incomprehensible \\
\hline 1 & & & & $\nabla$ & \\
\hline 2 & & & & $V$ & \\
\hline 3 & & & & & $V$ \\
\hline 4 & & & & & $V$ \\
\hline 5 & & & & & $V$ \\
\hline 6 & & & & $\nabla$ & \\
\hline 7 & & & & $\nabla$ & \\
\hline 8 & & & & & V \\
\hline 9 & & & & & $V$ \\
\hline 10 & & & & & \\
\hline 5.1 & $\begin{array}{l}\text { Very } \\
\text { good }\end{array}$ & Good & Average & $\mathrm{Bad}$ & Incomprehensible \\
\hline 1 & & $\boldsymbol{V}$ & & & \\
\hline 2 & & & $V$ & & \\
\hline 3 & & & $\mathbf{V}$ & & \\
\hline 4 & & & $V$ & & \\
\hline 5 & & $\boldsymbol{V}$ & & & \\
\hline 6 & & & V & & \\
\hline 7 & & & & $V$ & \\
\hline 8 & & & $V$ & & \\
\hline 9 & & & $V$ & & \\
\hline $\begin{array}{l}1 \\
0\end{array}$ & & & $V$ & & \\
\hline 5.2 & $\begin{array}{l}\text { Very } \\
\text { good }\end{array}$ & Good & Average & $\mathrm{Bad}$ & Incomprehensible \\
\hline 1 & $\mathbf{V}$ & & & & \\
\hline 2 & & $V$ & & & \\
\hline 3 & $\mathbf{V}$ & & & & \\
\hline 4 & $V$ & & & & \\
\hline 5 & $V$ & & & & \\
\hline 6 & & $\checkmark$ & & & \\
\hline 7 & & $\mathbf{V}$ & & & \\
\hline 8 & & $\nabla$ & & & \\
\hline 9 & $V$ & & & & \\
\hline 10 & $V$ & & & & \\
\hline
\end{tabular}

\section{Results and Conclusion}

As we can see, the evaluation shows a typical staggering tendency. Here is a group wise interpretation for better understanding:

8.1: Was the level eight control group. It was asked to translate the World History passage humanly. The evaluation shows staggering towards Good and Average with only response at Bad. 
8.2: This was level eight Experimental Group. It was asked to translate using electronic tools, a different World History passage. In other words, the machine translated this passage. The evaluation staggers towards Bad and Incomprehensible.

5.1: Was the level 5 Control Group who translated the scientific process humanly. The evaluation shows a concentration on Average.

5.2: This was the level 5 Experimental Group which shows results that are very significant to this study: When the machine translated a scientific process, results were concentrated at Very Good and Good.

It may be noted here that level eight students, in the final Semester of their B.A. programme, study three main courses which are, instantaneous translation, literary translation and translation problems. Thus, it can be said that their translation proficiency is slightly better than level five learners. The level five students are half way through with their BA eight-semester Programme. They are presently doing two Translation courses i.e., Theories Translation and Legal and Political Translation. These courses are undertaken after completing Introduction to Translation in Semester 4. s

Further, this study can conclude that MT is most successful as a translation tool in case of scientific materials where the nuances of language are not involved. To demonstrate my point, I fed certain English idioms for MT and the outcomes were hilarious.

Here are some linguistic jokes 'created' by Machine (Google) Translation:

It's raining cats and dogs

Machine translation: أنها تمطر القططو الكلاب

Human translation (done by me): تمطر السماء مِدرارً//يهطل المطر بغز ارة

- Watch out for yourself

Machine translation: احترس من نفسك

احترس لنفسك: Human translation

- One man's food is another man's poison

Machine translation: اللحم رجل واحد هو السملرجل آخر

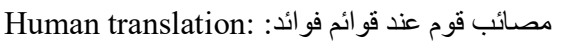

- Like a hen on a hot pan

Machine translation: إنه كدجاجة و اقفة على مقلاة حارة

Human translation: على أحر من الجمرة

\subsection{Recommandations}

MT is certainly a nascent field and it may be many years before it can completely replace human interpreters and translators. The range of human emotion and its concomitant, expression, is ever expanding and evolving. In the hands of inexperienced and untrained people, MT may prove to be a curse rather than a boon: Machine translated text should ideally be vetted by human experts. However, where the bulk of matter is gigantic but text is simple, MT can come in as a handy tool to provide the mush needed speed. In other circumstances, though, it is a potent tool to be used with caution. This is especially true in EFL situations as in Saudi Arabia where the student community is ill equipped to verify the reliability of machine translated texts.

\section{Acknowledgement}

I hereby present my heartfelt gratitude to my dear revered teacher Dr. Arif Ahmed Mohammed Al-Ahdal of Qassim University for the precious efforts he has made all through the process of my writing this paper. He has painstakingly yet cheerfully gone through this manuscript many a time and helped me greatly to bring it to this shape.

\section{References}

Advantages and disadvantages of machine translation. (n.d.). Retrieved from http://dilmanc.az/en/technology/mtadvantages

Aho, A.V., and ULLMAN, J.D. (1972). The theory of Parsing, Translation and

Compiling. Vol. 1: Parsing. Prentice Hall, Englewood Cliffs. NJ Arnold, D., Balkan, L., Meijer, S., Humphreys, R., \& Sadler, L. (1994). Machine translation: An introductory guide. London: NCC Blackwell.

Cautin, H. (1969). Real English: A translator to enable natural language man machine conversation. Thesis, Moore School Of Electrical Engineering, Univ. of Pennsylvania.

Craciunescu, O., Gerding-Salas, C., \& Stringer-O'Keeffe, S. (2008). Machine Translation and Computer-Assisted Translation (July). Retrieved from http://translationjournal.net/journal/29computers.htm

Hays, D. (1967). Introduction to Computational Linguistics. American Elsevier, New York 
How to Choose the Right Translation and Interpretation Service Provider [Advertisement]. (2014, September 17). Retrieved from http://nilservices.com/how-to-choose-the-right- translation-and-interpretation-service-provider/

Hutchins, J. (1995). Machine Translation: a brief history. Retrieved June 06, 2010, from http://aymara.org/biblio/mtranslation.pdf

Pym, A. (2012). On translator ethics: Principles for mediation between cultures. Amsterdam: John Benjamins Pub.

Petrick, S.R. (1973) Transformational Analysis. Natural Language Processing, R. Rustin, ed., Algorithmics Press, New York

PYM, Anthony. (2011). "What Technology Does to Translating", International Journal of Translating and Interpreting Research, 3(1), 1-9. http://www.transint.org/index.php/transint/article/viewFile/121/81 [10 pages]

Slocum, J. (1985). Machine Translation [Abstract]. Computers and the Humanities, 19(2, Natural Language Processing), 109-116.

Technology. (n.d.). The Free On-line Dictionary of Computing. Retrieved December 12, 2014, from Dictionary.com website: http://dictionary.reference.com/browse/technology.

Machine translation. (2014, December 4). Wikipedia, The Free Encyclopedia. Retrieved 21:17, December 18, 2014 , from http://en.wikipedia.org/w/index.php?title=Machine_translation\&oldid=636581844

Maia, B. (n.d.). Machine Translation and Human Translation: Using machine translation engines and corpora for teaching and research. Retrieved from http://web.letras.up.pt/bhsmaia/belinda/pubs/MTHT.doc

Woods, W.A. (1973) An experimental parsing system for transition network grammars. Natural Language Processing, R. Rustin, ed., Algorithmics Press, New York http://research.microsoft.com/en-us/projects/mt/

Koehn, Philip (2004). Statistical Significance Tests for Machine Translation Evaluation. EMNLP

Grishman, R. (1973). Implementation of the String Parser of English. Natural Language Processing, Randall Rustin, ed., Algorithmics Press

Rohrer, Christian. "Linguistic bases for machine translation." Proceedings of the 11th conference on Computational linguistics. Association for Computational Linguistics, 1986

Arnold, D. (1994). Machine translation: an introductory guide. Blackwell Publications:

Kay, Martin (1997). The Proper Place of Men and Machines in Language. Machine Translation, 12, 3-23. Kluver Academic Publications, Netherlands

Hoppe, Helena () Machine Translation Why Is It So Difficult? Linguistics C Level English Dept. of Humanities MidSweden University www.merriam-webster.com/dictionary/translation. 